\title{
The effect of depopulation and restocking on reproductive and growth performances on Japanese commercial swine farms
}

\author{
Yosuke SASAKI ${ }^{1,2)}$, Satoshi SEKIGUCHI ${ }^{2,3)}$, Ryoko UEMURA ${ }^{2,4)}$ and Masuo SUEYOSHI ${ }^{2,4) *}$ \\ 1) Organization for Promotion of Tenure Track, University of Miyazaki, Miyazaki 889-2192, Japan \\ ${ }^{2)}$ Center for Animal Disease Control, University of Miyazaki, Miyazaki 889-2192, Japan \\ ${ }^{3)}$ Laboratory of Animal Infection Disease and Prevention, Graduate School of Medicine and Veterinary Medicine, University of Miyazaki, \\ Miyazaki 889-2192, Japan \\ 4)Laboratory of Animal Health, Department of Veterinary Sciences, Faculty of Agriculture, University of Miyazaki, Miyazaki 889-2192, \\ Japan
}

(Received 7 January 2015/Accepted 15 September 2015/Published online in J-STAGE 27 September 2015)

ABSTRACT. This study compared the reproductive and growth performances of pigs before and after depopulation and restocking after a foot-and-mouth disease outbreak in Japan. Data for the time period before and after depopulation and restocking were obtained from three farrow-to-finish farms. As a result of depopulation and restocking, hygiene levels were improved, and common infectious diseases, such as porcine reproductive and respiratory syndrome and Aujeszky's disease, remained undetected on the farms. Compared with before depopulation, reproductive and growth performances improved after depopulation; the number of total pigs born was higher, the postweaning mortality rate was lower, and the age at slaughter was lower $(P<0.05)$. In summary, depopulation and restocking improved the reproductive and growth performances of pigs.

KEY WORDS: depopulation, FMD, reproductive performance, restocking, swine

doi: 10.1292/jvms.15-0013; J. Vet. Med. Sci. 78(2): 333-335, 2016

Miyazaki Prefecture, on the southern island of Kyushu, is a major swine-producing area in Japan. In April 2010, a footand-mouth disease (FMD) outbreak occurred. To eradicate it, ring vaccination coupled with the depopulation of cattle and pig herds was performed in the most severely affected areas. As a result, FMD was eradicated by August 2010, and swine producers in the affected areas began farming again in November 2010. At the time of restocking, the swine producers implemented control programs to keep the area free from major infectious diseases including porcine reproductive and respiratory syndrome (PRRS) and Aujeszky's disease (AD). To understand the effect of depopulation and restocking, we aimed to assess the reproductive and growth performances before and after FMD eradication.

The present study was conducted in the suburban areas of the town of Kawaminami, Miyazaki Prefecture, Japan. The town, located at a longitude of $131^{\circ} 52^{\prime} \mathrm{E}$ and latitude of $32^{\circ}$ $19^{\prime} \mathrm{N}$, has a high density of pig farms $\left(1.05 / \mathrm{km}^{2}\right)$. Because of the FMD outbreak in April 2010, all cattle and pigs in the town were euthanized to prevent the spread of the infection. As both PRRS and AD were endemic and controlled by vaccination in this region before the FMD outbreak, strict control programs were implemented to eradicate them at the time of restocking. The controls were as follows: producers

*Correspondence to: Sueyoshi, M., Center for Animal Disease Control, University of Miyazaki, 1-1 Gakuen Kibanadai-nishi, Miyazaki 889-2192, Japan. e-mail: a0d802u@cc.miyazaki-u.ac.jp (C)2016 The Japanese Society of Veterinary Science

This is an open-access article distributed under the terms of the Creative Commons Attribution Non-Commercial No Derivatives (by-nc-nd) License $<$ http://creativecommons.org/licenses/by-nc-nd/3.0/>. had to obtain new pigs, such as replacement gilts or weaned pigs, from PRRS- and AD-negative farms; the new gilts or sows had to have negative results from PRRS and AD tests before they could leave the farm of origin and after they arrived at the new farm; and 14 randomly selected pigs had to be tested for PRRS and AD twice per year with negative results. For PRRS and AD, blood samples were tested using PCR and ELISA.

To determine reproductive and growth performances, the farms selected in the study area had to possess the following data: (1) parity records of sows in an electronic form; (2) monthly records of growth performance; and (3) both of these records before and after the FMD outbreak. Parity records had to contain data on sow identification, parity, farrowing date, total pigs born, pigs born alive, pigs born dead, piglet weight at birth, date of weaning, number of pigs weaned, piglet weight at weaning and date of service and conception. Growth performance comprised data on postweaning mortality, age at slaughter for market pigs and average daily gain in the postweaning stage. As a result, three farrow-to-finish farms with complete records of reproductive and growth performances before and after the FMD outbreak were selected and used for further analysis. The number of sows which had breeding operations during the study period on these three farms ranged from 400 to 720 . The female pigs were $F_{1}$ crossbreds of Landrace and Large White, obtained from a domestic breeding company.

The values of the production variables were compared between the pre-depopulation period (conditions before the FMD outbreak) and the post-depopulation period (conditions after the FMD outbreak). The data for the pre-depopulation period were collected from January 2008 to March 2010 
and for the post-depopulation period from January 2011 to July 2012. Regarding data for the post-depopulation period, mating performance data were available from January 2011 to July 2012 and farrowing and weaning performance data from April 2011 to July 2012. The reproductive data from 12,496 parity records of 3,757 sows were used for the present study. Growth performance data were available from January 2008 to March 2010 and from August 2011 to July 2012. The growth performance data were calculated as the sum of the monthly values of each growth performance measure divided by the number of monthly records at each of the three farms.

A linear mixed-effects model was applied to continuous data, and a mixed-effects logistic regression model was applied to binomial data (SAS Institute Inc., Cary, NC, U.S.A.). The observational unit for comparing reproductive performance was parity. The dependent variable was reproductive performance, and the independent variables were the pre-depopulation and post-depopulation periods with the farm added to the model as a random effect. The observational unit for comparing growth performance was the farm. The dependent variables were growth performance, and the independent variables were the pre-depopulation and postdepopulation periods.

The average parities of sows in the pre-depopulation and post-depopulation periods were 3.8 (range: 1-11) and 2.3 (range: 1-4), respectively. Because of the small number of records with a parity of 4 in the post-depopulation period, comparisons of reproductive performance were applied to parities 1 to 3 . Tables 1 and 2 show a comparison of the reproductive performance between the pre-depopulation and post-depopulation periods for sows with a parity from 1 to 3 . In terms of the farrowing performance, sows in the post-depopulation period had a higher number of total pigs born and pigs born alive than those in the pre-depopulation period at parities 1 to $3(P<0.05)$. No differences were found between the two periods in the number of pigs born dead or the piglet weight at birth. In the analysis of weaning and mating performances, piglet weight at weaning in the postdepopulation period was approximately $1 \mathrm{~kg}$ higher than that in the pre-depopulation period at parities 1 to $3(P<0.05)$. For sows with a parity of 1 , the preweaning mortality rate in the post-depopulation period was higher than in the predepopulation period $(P<0.05)$. This could have been caused, at least in part, by Staphylococcus hyicus infection, which is associated with high mortality [4] and occurred at the beginning of the period after depopulation on two farms. In contrast, sows in the post-depopulation period had longer weaning-to-first-mating intervals at parity 3 , but higher farrowing rates at parity 2 than those of sows in the predepopulation period $(P<0.05)$. This was because all three farms hesitated to cull sows with reproductive problems in order to maintain the farm's female inventory after restocking. Even under such regulation, the higher farrowing rate at parity 2 and the higher piglet weight at weaning in the post-depopulation period compared with the pre-depopulation period indicated that depopulation and restocking had increased the breeding productivity in each herd. No
Table 1. Comparison of farrowing performance between the predepopulation and post-depopulation periods

\begin{tabular}{|c|c|c|c|}
\hline & \multicolumn{3}{|c|}{ Parity } \\
\hline & 1 & 2 & 3 \\
\hline \multicolumn{4}{|l|}{ Total pigs born (pigs) } \\
\hline Pre-depopulation period & $11.0 \pm 0.07^{\mathrm{b})}$ & $11.3 \pm 0.08^{\mathrm{b})}$ & $11.9 \pm 0.09^{\mathrm{b})}$ \\
\hline Post-depopulation period & $11.8 \pm 0.07^{\mathrm{a})}$ & $12.0 \pm 0.10^{\mathrm{a})}$ & $13.0 \pm 0.10^{\mathrm{a})}$ \\
\hline \multicolumn{4}{|l|}{ Pigs born alive (pigs) } \\
\hline Pre-depopulation period & $10.2 \pm 0.07^{\mathrm{b})}$ & $10.7 \pm 0.08^{\mathrm{b})}$ & $11.2 \pm 0.08^{\mathrm{b})}$ \\
\hline Post-depopulation period & $11.1 \pm 0.07^{\mathrm{a})}$ & $11.4 \pm 0.10^{\mathrm{a})}$ & $12.2 \pm 0.10^{\mathrm{a})}$ \\
\hline \multicolumn{4}{|l|}{ Pigs born dead (pigs) } \\
\hline Pre-depopulation period & $0.8 \pm 0.03$ & $0.6 \pm 0.03$ & $0.7 \pm 0.04$ \\
\hline Post-depopulation period & $0.7 \pm 0.03$ & $0.6 \pm 0.03$ & $0.8 \pm 0.04$ \\
\hline \multicolumn{4}{|l|}{ Piglet weight at birth $(\mathrm{kg})$} \\
\hline Pre-depopulation period & $1.4 \pm 0.01$ & $1.5 \pm 0.01$ & $1.5 \pm 0.01$ \\
\hline Post-depopulation period & $1.4 \pm 0.01$ & $1.5 \pm 0.01$ & $1.5 \pm 0.01$ \\
\hline
\end{tabular}

Mean values within a column for each measurement with different letters were significantly different between the pre-depopulation and postdepopulation periods $(P<0.05)$ (mean \pm SEM).

Table 2. Comparison of weaning and mating performances between the pre-depopulation and post-depopulation periods

\begin{tabular}{|c|c|c|c|}
\hline & \multicolumn{3}{|c|}{ Parity } \\
\hline & 1 & 2 & 3 \\
\hline \multicolumn{4}{|l|}{ Number of pigs weaned (pigs) } \\
\hline Pre-depopulation period & $10.3 \pm 0.05$ & $10.3 \pm 0.05$ & $10.3 \pm 0.05$ \\
\hline Post-depopulation period & $10.1 \pm 0.06$ & $10.5 \pm 0.05$ & $10.7 \pm 0.08$ \\
\hline \multicolumn{4}{|l|}{ Preweaning mortality (\%) } \\
\hline Pre-depopulation period & $6.6 \pm 0.38^{\mathrm{b})}$ & $6.5 \pm 0.36$ & $6.4 \pm 0.34$ \\
\hline Post-depopulation period & $10.3 \pm 0.48^{\mathrm{a})}$ & $8.0 \pm 0.35$ & $9.3 \pm 0.38$ \\
\hline \multicolumn{4}{|l|}{ Piglet weight at weaning $(\mathrm{kg})$} \\
\hline Pre-depopulation period & $7.7 \pm 0.02^{b)}$ & $7.8 \pm 0.03^{b)}$ & $7.7 \pm 0.03^{b)}$ \\
\hline Post-depopulation period & $8.8 \pm 0.05^{\mathrm{a})}$ & $8.7 \pm 0.03^{\mathrm{a})}$ & $8.8 \pm 0.03^{\mathrm{a})}$ \\
\hline \multicolumn{4}{|c|}{ Weaning-to-first-mating interval (days) } \\
\hline Pre-depopulation period & $12.5 \pm 0.53$ & $8.7 \pm 0.41$ & $8.0 \pm 0.36^{\mathrm{b})}$ \\
\hline Post-depopulation period & $12.1 \pm 0.44$ & $9.0 \pm 0.31$ & $9.5 \pm 0.38^{\mathrm{a})}$ \\
\hline \multicolumn{4}{|l|}{ Farrowing rate $(\%) c$} \\
\hline Pre-depopulation period & $86.6 \pm 0.80$ & $82.6 \pm 0.99$ & $88.6 \pm 0.84^{b)}$ \\
\hline Post-depopulation period & $87.3 \pm 0.83$ & $84.9 \pm 0.97$ & $94.2 \pm 0.73^{\mathrm{a})}$ \\
\hline
\end{tabular}

Mean values within a column for each measurement with different letters were significantly different between the pre-depopulation and postdepopulation periods $(P<0.05)$. c) Values in the left, middle and right columns are the farrowing rates for parities of 0,1 and 2, respectively. $($ mean $\pm \mathrm{SEM})$.

difference was found between the two period groups in the number of pigs weaned. In terms of growth performance, the post-depopulation period had a lower postweaning mortality rate, a lower age at slaughter and higher average daily gain than those of the pre-depopulation period $(P<0.05$; Table 3$)$.

This is the first report to quantify the effect of depopulation and restocking on both the reproductive and growth performances of pigs on Japanese commercial farms. The present study has indicated that depopulation and the subsequent introduction of stock can improve reproductive and growth performances. One possible factor relating to this 
Table 3. Comparison of growth performance between the predepopulation and post-depopulation periods

\begin{tabular}{lcc}
\hline & $\begin{array}{c}\text { Pre-depopulation } \\
\text { period }\end{array}$ & $\begin{array}{c}\text { Post-depopulation } \\
\text { period }\end{array}$ \\
\hline Postweaning mortality (\%) & $7.9 \pm 1.94^{\mathrm{a})}$ & $3.3 \pm 0.15^{\mathrm{b})}$ \\
Age at slaughter (day) & $186.7 \pm 9.83^{\mathrm{a})}$ & $166.5 \pm 1.71^{\mathrm{b}}$ \\
Average daily gain (g) & $615.4 \pm 37.14^{\mathrm{a})}$ & $690.7 \pm 6.89^{\mathrm{b})}$ \\
\hline
\end{tabular}

Mean values with different letters within a row were significantly different $(P<0.05)$ (mean \pm SEM).

improvement could be the better hygienic environment of the farms as a result of the cleaning and disinfection between the depopulation and restocking periods. Depopulation and restocking might also have led to a reduction in the infection pressure of various pathogenic viruses and improved the producers' attitudes towards implementing preventive measures against infectious diseases.

After restocking, swine producers implemented strict control programs to eradicate PRRS and AD. Better reproductive and growth performances in the post-depopulation period than in the pre-depopulation period could be supported by these control programs, because PRRS and AD reportedly decrease both reproductive and growth performances $[1-3,9]$. PRRS is currently endemic in the major swine-producing regions of the world [10] and imposes a substantial economic burden on swine producers, estimated at US \$664 million annually in U.S.A. [5, 9]. In Japan, PRRS is wide spread throughout almost all swine-producing areas and impairs production performance. $\mathrm{AD}$ is also endemic in Japan, causing significant economic losses [7, 8]. In addition, PRRS and AD infections also predispose pigs to infection by pathogens, such as Mycoplasma spp. [6]. For these reasons, it is important to eradicate PRRS and AD to improve and enhance the productivity of swine producers.

One limitation of this study is that only a relatively small number of farming operations could provide the necessary records. In the study area, most producers recorded the performance of sows and fattening pigs on paper, so their records had to be incinerated or buried with the FMDaffected or -suspected animals. Most farms maintained their productivity records after FMD eradication. However, to compare productivity before and after restocking, farms with no records for the period before restocking had to be excluded from the present study. However, our pre-study interviews with swine producers in this area revealed that growth performance had improved in the post-depopulation period. Furthermore, other respiratory disorders caused by Mycoplasma hyopneumoniae or Actinobacillus pleuropneumoniae infections may also have affected the results. Although the status of both respiratory disorders was positive after restocking the studied farms, it is difficult to determine the degree of improvement after restocking because of the lack of data on the status of these diseases before restocking.

ACKNOWLEDGMENTS. The authors gratefully thank the swine producers for their cooperation in this project. This work was supported by a KAKENHI (Grants-in-Aid for Scientific Research) from the Japan Society for the Promotion of Science (No. 26870454).

\section{REFERENCES}

1. Christianson, W. T. and Joo, H. S. 1994. Porcine reproductive and respiratory syndrome: A review. J. Swine Health Prod. 2: $10-28$.

2. Dee, S. A., Joo, H. S., Polson, D. D. and Marsh, W. E. 1997. Evaluation of the effects of nursery depopulation of the profitability of 34 pig farms. Vet. Rec. 140: 498-500. [Medline] [CrossRef]

3. Dewey, C. E., Wilson, S., Buck, P. and Leyenaar, J. K. 1999. The reproductive performance of sows after PRRS vaccination depends on stage of gestation. Prev. Vet. Med. 40: 233-241. [Medline] [CrossRef]

4. Frana, T. S. 2012. Staphylococcosis. pp. 834-840. In: Diseases of Swine., 10th ed. (Zimmerman, J. J., Karriker, L. A., Ramirez, A., Schwartz, K. J. and Stevenson, G. W. eds.), Blackwell Publishing, West Sussex.

5. Holtkamp, D. J., Kliebenstein, J. B., Neumann, E. J., Zimmerman, J. J., Rotto, H. F., Yoder, T. K., Wang, C., Yeske, P. E., Mowrer, C. L. and Haley, C. A. 2013. Assessment of the economic impact of porcine reproductive and respiratory syndrome virus on United States pork producers. J. Swine Health Prod. 21: $72-84$.

6. Kawashima, K., Yamada, S., Kobayashi, H. and Narita, M. 1996. Detection of porcine reproductive and respiratory syndrome virus and Mycoplasma hyorhinis antigens in pulmonary lesions of pigs suffering from respiratory distress. J. Comp. Pathol. 114: 315-323. [Medline] [CrossRef]

7. Martínez-López, B., Carpenter, T. E. and Sánchez-Vizcaíno, J. M. 2009. Risk assessment and cost-effectiveness analysis of Aujeszky's disease virus introduction through breeding and fattening pig movements into Spain. Prev. Vet. Med. 90: 10-16. [Medline] [CrossRef]

8. Mettenleiter, T. C., Ehlers, B., Müller, T., Yoon, K.J. and Teifke, J. P. 2012. Herpesviruses. pp. 421-446. In: Diseases of Swine., 10th ed. (Zimmerman, J. J., Karriker, L. A., Ramirez, A., Schwartz, K. J. and Stevenson, G. W. eds.), Blackwell Publishing, West Sussex.

9. Neumann, E. J., Kliebenstein, J. B., Johnson, C. D., Mabry, J. W., Bush, E. J., Seitzinger, A. H., Green, A. L. and Zimmerman, J. J. 2005. Assessment of the economic impact of porcine reproductive and respiratory syndrome on swine production in the United States. J. Am. Vet. Med. Assoc. 227: 385-392. [Medline] [CrossRef]

10. Zimmerman, J. J., Benfield, D. A., Dee, S. A., Murtaugh, M. P., Stadejek, T., Stevenson, G. W. and Torremorell, M. 2012. Porcine reproductive and respiratory syndrome virus (Porcine arterivirus). pp. 461-486. In: Diseases of Swine., 10th ed. (Zimmerman, J. J., Karriker, L. A., Ramirez, A., Schwartz, K. J. and Stevenson, G. W. eds.), Blackwell Publishing, West Sussex. 